\title{
Diferenças entre os processos de contratação da organização pública e privada
}

\author{
Differences between the public and private \\ organization hiring processes
}

Giseli Passador Lombardi Universidade Guarulhos

Eliane Suguimoto Laureano Universidade Guarulhos

Antonio Carlos Estender Universidade Guarulhos

Resumo Este artigo se propõe a abordar quais são as práticas nos processos de contratação de pessoal da Organização Pública e da Privada, visando compreender sua execução, suas peculiaridades e suas percepções acerca desse tema. Tem como objetivo demonstrar as diferenças na área administrativa. A pesquisa foi realizada por intermédio da pesquisa de campo, entre colaboradores do setor público e do privado, onde foram realizadas 24 entrevistas de natureza qualitativa e exploratória, sendo a coleta de dados efetuada por meio de questionário. Como principais resultados, observamos sugestões como: a inclusão no edital de concurso público de uma $2^{\mathrm{a}}$ fase classificatória e testes com psicólogos; e nas organizações privadas, para que não haja desvio de função, o aperfeiçoamento da descrição de cargos e funções, bem como, a inserção de pesquisa de satisfação para os stakeholders. Diante do exposto, as implicações mais relevantes foram no caso das organizações públicas, a proposta de mudança na legislação em vigor para diminuir a porcentagem de comissionados, enquanto que nas instituições privadas, identificamos a necessidade de melhoria na imagem da organização como modo de atrair colaboradores.

Palavras-chave: Processo. Práticas. Setor público. Setor privado. 
Abstract This article proposes to discuss the practices in the hiring processes of Public and Private Organization personnel, in order to understand their execution, their peculiarities and their perceptions about this topic. It aims to demonstrate the differences in the administrative area. The research was carried out through a field study between public and private sector employees, in which 24 interviews of qualitative and exploratory nature were conducted, and the data collection was done through the use of a questionnaire. As main results, we observed suggestions such as: the inclusion of a $2^{\text {nd }}$ classifying phase and tests with psychologists in the public notice of selective examand in the private organizations, so that there is no deviation of function, the improvement of job descriptions and functions, as well, as the application of satisfaction survey for the stakeholders. Considering the above, the most relevant implications were, in the case of public organizations, the proposed change in the legislation in force to reduce the percentage of commissioned personnel, while in private institutions we identified the need to improve the image of the organization as a way to attract employees.

Key-words: Process. Practices. Public sector. Private sector.

\section{INTRODUÇÃO}

A importância desta pesquisa nos dias atuais é pertinente, devido às mudanças que entraram em vigor a partir de novembro do presente ano, que alteraram a legislação trabalhista, causando muitas dúvidas e insegurança aos trabalhadores e empresários. Dados divulgados pela EBC Agência Brasil, a respeito das novas regras, alteram alguns conceitos sobre férias, jornada de trabalho e relação de sindicatos. No total, foram alterados mais de 100 artigos da Consolidação das Leis do Trabalho (CLT).

Outro dado significativo se refere à taxa de desemprego no Brasil que, segundo o portal Valor Econômico (2017), é de 13,3\%, ou seja, 13,771 milhões de pessoas desempregadas. Esses dados foram divulgados conforme a Pesquisa Nacional por Amostra de Domicílios (PNAD), do Instituto Brasileiro de Geografia e Estatística (IBGE), no trimestre finalizado em maio de 2017.

A República Federativa do Brasil é formada pela união indissolúvel dos Estados, Municípios e do Distrito Federal, e se constitui em 
Estado Democrático de Direito, sendo poderes da União, independentes e harmônicos entre si, o Legislativo, o Executivo e o Judiciário, conforme a Constituição Federal de 1988, artigos $1^{\circ}$. e $2^{\circ}$.

Segundo Martins (2006), a Administração Pública pode ser entendida como Poder Executivo, sendo dividida em Administração Pública Direta, que abrange os serviços prestados pela própria Administração e a Administração Pública Indireta, que é constituída ${ }^{1}$ pelas sociedades de economia mista, empresas públicas (que exploram a atividade econômica), fundações públicas e pelas autarquias. De acordo com o artigo 37, "caput", da Constituição Federal, todos que fazem parte da Administração Pública Direta ou Indireta de qualquer dos Poderes da União obedecerão aos princípios ${ }^{2}$ da legalidade, impessoalidade, moralidade, publicidade e eficiência.

O setor privado é o agrupamento da atividade econômica que não é controlada pelo Estado e o seu componente principal é a empresa, que pode ser individual, com vários sócios, ou na forma de sociedade limitada, anônima ou coletiva. O seu objetivo é econômico e por meio de produtos ou serviços. ${ }^{3}$

\footnotetext{
MARTINS, S. P. Instituições de Direito Público e Privado, 6. ed. São Paulo: Atlas, 2006, p. 106 e 107. Sociedade de economia mista: entidades de direito privado criadas por lei para exploração de atividade econômica, sob a forma de sociedade anônima; maioria do capital pertence ao Poder Executivo. Ex.: Petrobrás; Empresas Públicas: entidades de direito privado com patrimônio próprio e capital exclusivo do Poder Executivo, criadas por lei para a exploração de atividade econômica. Ex.: Embratel; Fundações Públicas: pessoas jurídicas de direito privado, sem fins lucrativos, desde que autorizada por lei composta de patrimônio próprio e destacado do fundador, visando determinada finalidade. Ex.: Fundação Casa; Autarquias: órgãos autônomos criados por lei com personalidade jurídica, patrimônio e receita própria para executar atividades da Administração Pública e requeiram para melhor gestão funcionamento gestão administrativa e financeira descentralizada. Ex.: INSS.

2 MARTINS, S. P. Instituições de Direito Público e Privado, 6. ed. São Paulo: Atlas, 2006, p.107 e 108. Legalidade: Administração Pública faz apenas aquilo que a lei determina; Impessoalidade: os atos não devem ser voltados à satisfação de determinadas pessoas e sim ao interesse público; Moralidade: envolve probidade administrativa, honestidade; Publicidade: é a divulgação oficial do ato administrativo para o conhecimento público; Eficiência: deve desenvolver os serviços com presteza e perfeição visando aos resultados almejados pelo público.

3 Disponível em: http://queconceito.com.br/setor-privado
} 
Buscando compreender os seguintes questionamentos de como são as Práticas nos Processos de Contratação entre o Setor Público e o Privado, por que as Práticas de Contratação entre o Setor Público e o Privado são divergentes, e quais as características nos Processos de Contratação entre o Setor Público e o Privado, foi desenvolvida a presente pesquisa.

Segundo o Portal de Pesquisas Temáticas e Educacionais (2017), as principais causas do desemprego são a baixa qualificação do trabalhador, substituição de mão de obra por máquinas, crise econômica, alto custo dos impostos e encargos para as empresas contratarem com carteira assinada, fatores climáticos.

A finalidade deste trabalho é melhorar o entendimento sobre os processos e expor os diferentes aspectos da contratação entre o Setor Público e o Privado; comparar esses processos de contratação; realizar levantamento das percepções dos colaboradores; analisar o quadro de percepções, fatos, situações e processos, a fim de identificar e examinar as relações existentes entre os entrevistados; apontar as semelhanças e diferenças entre a literatura e os resultados obtidos com as entrevistas; elaborar ações ancoradas nas percepções das situações vivenciadas pelos entrevistados para a produção de ações que possibilitem atingir os objetivos.

\section{REVISÃo DE LITERATURA}

\subsection{Processos de contratação nas instituições públicas}

A contratação de pessoal nas instituições públicas deve obedecer à Constituição Federal, artigo 37, inciso II, o qual estabelece que a investidura em cargo ou emprego público depende de aprovação prévia em concurso público de provas ou de provas e títulos, conforme a natureza e a complexidade do cargo ou emprego, na forma prevista em lei, exceto as nomeações para cargo em comissão, que são declarados em lei de livre nomeação e exoneração. 
O Brasil adota a forma federativa ${ }^{4}$ de partilhar o poder entre os seus entes: a União, Estados, Distrito Federal e Municípios. São todos pessoas jurídicas de Direito Público com capacidade política e podem criar suas próprias leis, segundo Martins; Passos (2002).

Tendo em vista que cada ente da Federação tem competência para criar leis referentes ao processo de contratação, utilizaremos como exemplo a Administração Pública Estadual de São Paulo, que é regida pela Lei no ${ }^{\circ}$ 10.261, de 28/10/1968 - Estatuto dos Funcionários Públicos do Estado de São Paulo. Porém, antes de o edital ser publicado, normalmente, segue o seguinte rito:

1. Proposta para abertura de concurso público em decorrência de vagas de aposentadorias, exonerações ou mortes ou de lei que criam vagas;

2. Encaminhamento de convite para três instituições, conforme as regras da Lei de Licitações e Contratos, Lei no ${ }^{\circ}$. 8.666/93;

3. Comissão de servidores para o acompanhamento do concurso;

4. Definição da instituição após análise dos orçamentos;

5. Contratação por meio de dispensa de licitação, conforme artigo 24, inciso XIII, da Lei ${ }^{\circ}$. 8.666/93, que descreve:

Artigo 24. É dispensável a licitação:

\begin{abstract}
XIII - na contratação de instituição brasileira incumbida regimental ou estatutariamente da pesquisa, do ensino ou do desenvolvimento institucional, ou de instituição dedicada à recuperação social do preso, desde que a contratada detenha inquestionável reputação éticoprofissional e não tenha fins lucrativos.
\end{abstract}

6. Publicação do edital no Diário Oficial do Estado de São Paulo do concurso público, especificando os requisitos, grau de escolaridade, validade do concurso, relação de exames, con-

Artigo 18 CF/88 - A organização político-administrativa da República Federativa do Brasil compreende a União, os Estados, o Distrito Federal e os Municípios, todos autônomos, nos termos desta Constituição. 
teúdo programático, data da prova, entre outras informações necessárias para concorrer ao cargo público, em conformidade com a Lei $\mathrm{n}^{\circ}$. 10.261/68;

7. Após aprovação na prova, o candidato será nomeado, devendo comparecer ao órgão com os documentos solicitados. Depois da validação de todos os exames médicos e documentação entregue, será o momento da posse do cargo e posterior exercício.

\subsection{Processos de contratação nas instituições privadas}

Já na Instituição Privada, a contratação de pessoal é feita por meio do recrutamento e seleção. De acordo com Chiavenato (2009), o recrutamento envolve um processo que é alterado conforme a instituição. $\mathrm{O}$ início do processo depende de uma decisão de linha, ou seja, do gerente; uma vez que essa decisão não pode ser tomada individualmente e sim em conjunto com a gerência, para que não haja impactos negativos no setor financeiro.

O recrutamento "constitui o elo entre organização e mercado de trabalho que atua como ponto de referência que une candidato à empresa" (CARVALHO et al. (2016, p. 92). Para o autor, também é importante saber o grau de competência, perfil de RH da empresa, levantamento de necessidades, etapas, entre outros dados antes de iniciar o processo de recrutamento; de forma que essa fase é muito importante, é preciso saber com antecedência a quantidade de colaboradores e para que área estão sendo recrutados, a empresa conseguirá seguir com o seu planejamento estratégico.

O recrutamento deverá ser de acordo com a necessidade de substituir uma pessoa que se desligou da organização ou que foi promovida/ transferida e que não há sucessor, uma decisão estratégica da empresa que exige a rápida busca de novas competências para empregar uma nova tecnologia, mas que seus colaboradores não a dominam ou, então, uma expectativa de aumento na produção; com essa visão, por conseguinte, a empresa ficará sempre com seu quadro de pessoal completo, conforme as necessidades de reposição (PEQUENO, 2012). 
Recrutamento pode ser definido como "atração de mão-de-obra" (PONTES, 2001). Quanto melhor for a imagem da empresa, tanto maior será a facilidade no recrutamento externo. Para o autor, o recrutamento possui duas fontes: o interno (valorização dos colaboradores que trabalham internamente) e o externo (contratação de pessoas de fora da empresa para melhorar e modernizar as ideias da empresa); portanto, é imprescindível que a empresa tenha nome para atrair colaboradores dispostos a se dedicar e a se empenhar.

A seleção é a escolha, entre os candidatos recrutados, os que melhor se enquadram no cargo vago e na necessidade organizacional, objetivando manter ou aumentar a eficiência, desempenho de pessoal e a eficácia da organização (CHIAVENATO, 2009). A seleção tem como objetivo resolver dois problemas, ou seja, adequar a pessoa ao cargo ou vice-versa ou adequar as competências individuais da pessoa às competências organizacionais almejadas pela empresa, e também, eficiência e satisfação da pessoa no cargo ou provisão das competências que a empresa espera; apesar de muitas empresas não terem essa preocupação com o seu colaborador, é importante pensar no seu bem-estar, para que consiga ser mais eficiente.

A seleção consiste em um processo sistêmico que tem por finalidade escolher, entre os candidatos recrutados, aquele que contemple o perfil traçado pela empresa para ocupar o cargo em questão (CARVALHO et al., 2016). O autor deixa claro que recrutamento e seleção são duas etapas que fazem parte de um mesmo processo; além de tudo, no recrutamento o selecionador saberá quem poderá fazer parte da etapa seguinte e uma seleção bem constituída e impessoal conseguirá escolher os melhores futuros colaboradores que contribuirão para o crescimento da empresa.

Deve-se ter muito cuidado ao selecionar o colaborador, porque o desempenho de quem contrata e da empresa, em partes, depende do desempenho desse candidato. Se for uma pessoa que causa problemas e não possui atributos e habilidades, prejudicará a todos, criando altos custos e até implicações na justiça. Testes, verificação de antecedentes, referências e entrevistas também devem ser utilizados, pois são instru- 
mentos importantes para analisar; além disso, precaver-se de uma contratação mal realizada evitará aborrecimentos futuros e não atrapalhará a equipe (DESSLER, 2003).

Para Pontes (2001), a seleção de pessoal é bilateral e não deve levar em conta apenas a qualificação e o potencial, porque as pessoas têm necessidades diferentes, o que deve ser levado em conta no processo seletivo, uma vez que isso surtirá efeitos no seu desempenho futuro. É importante verificar se as suas necessidades fisiológicas, de segurança sociais, estima e autorrealização podem ser satisfeitas no cargo e na empresa; em suma, se a organização agir e pensar dessa maneira, com certeza alcançará suas metas de seu planejamento estratégico.

\section{Estratégias de PESQUiSa}

O método de pesquisa deste trabalho foi por meio da pesquisa de campo, que, conforme Severino (2007), o objeto/fonte é abordado em seu meio ambiente próprio e a coleta dos dados é feita nas condições naturais em que os fenômenos ocorrem, sem a interferência do pesquisador. Também foi utilizada a pesquisa exploratória que, de acordo com Gil (2002), possibilita maior familiaridade com o problema para deixá-lo mais evidente ou para criar hipóteses. O objetivo principal é o aprimoramento de ideias ou a descoberta de intuições, sendo o seu planejamento flexível, o que possibilita considerações dos mais diversos aspectos referentes ao objeto da pesquisa.

O aporte teórico foi imprescindível para a elaboração dos questionários, para o desenvolvimento dos métodos empregados, bem como, para a análise dos resultados obtidos.

O questionário possui sete questões. No presente estudo, responderam aos questionários 24 pessoas, sendo que deles 12 eram funcionários do setor público e 12 do setor privado.

Após a coleta dos dados para analisar os resultados das informações discursivas, procedeu-se à análise de conteúdo (FRANCO, 2012). Inicialmente, foi feita uma leitura flutuante que, de acordo com Franco, é a "primeira atividade da Pré-Análise", e "consiste em estabelecer con- 
tatos com os documentos a serem analisados e conhecer os textos e as mensagens neles contidas, deixando-se invadir por impressões, representações, emoções, conhecimentos e expectativas" (FRANCO, 2012, p. 54).

Na sequência, foi realizada a categorização “[...] que é uma operação de classificação de elementos constitutivos de um conjunto, por diferenciação seguida de um reagrupamento baseado em analogias, a partir de critérios definidos" (FRANCO, 2012, p. 63). O critério de categorização escolhido foi o semântico (categorias temáticas).

O processo de contratação no Setor Público é feito por intermédio do edital de concurso público, onde estarão discriminados o nível de escolaridade exigido, documentos, conteúdo para a(s) prova(s), exames médicos, entre outros dados, conforme a lei.

Já no Setor Privado, o processo é por meio do recrutamento e seleção. Cada empresa possui uma maneira própria de elaborar seus processos.

\section{ApresentaÇão e anÁlise dos resultados}

Os resultados descritos a seguir têm como base as informações colhidas nas entrevistas que contribuíram para o estudo, que visaram responder sobre as diferenças entre a contratação de pessoas no Setor Público e no Setor Privado. As discussões apresentadas buscam traduzir a interpretação do pesquisador, construída a partir da análise das respostas obtidas, bem como, dos dados obtidos a partir da observação in loco. As informações foram trabalhadas de forma a exibir as percepções dos colaboradores de ambas as instituições, com a finalidade de elaborar ações que venham a contribuir para um melhor entendimento a respeito do assunto e aprimoramento no ambiente organizacional.

A seguir, serão analisadas as evocações obtidas com as respostas dos empregados ao questionário aplicado: 
Quadro 1. O que acha e qual a principal diferença no processo de contratação de pessoal?

\begin{tabular}{|c|c|c|c|}
\hline \multicolumn{2}{|c|}{ SETOR PÚBLICO } & \multicolumn{2}{|l|}{ SETOR PRIVADO } \\
\hline Evocação & Frequência & Evocação & Frequência \\
\hline Concurso Público & 10 & Currículo & 3 \\
\hline Comissionados & 3 & Estratégia de análise para contratação & 3 \\
\hline Igualdade & 3 & Avaliação por meio de testes & 2 \\
\hline Depende do candidato & 2 & Contratação por indicação & 2 \\
\hline Objetividade & 2 & Contratação sem critérios-pessoal & 2 \\
\hline Pré-requisitos em Lei & 2 & Flexibilidade no setor privado & 1 \\
\hline Acesso é amplo & 1 & Habilitada para atuar em mais áreas & 1 \\
\hline Impessoalidade & 1 & Maior praticidade & 1 \\
\hline Não depende de entrevista & 1 & Menos burocráticos & 1 \\
\hline Órgão não escolhe o candidato & 1 & Vaga através do jornal & 1 \\
\hline
\end{tabular}

Fonte: Dados da pesquisa

Nas Instituições Públicas, verificou-se que a maioria dos respondentes entende que o diferencial está no concurso público, porque existe igualdade entre os participantes, exceto para os comissionados, os pré-requisitos são determinados e a aprovação depende somente do candidato, enquanto que nas instituições privadas a contratação é feita por meio de análise do currículo, testes são aplicados como avaliação, cada empresa utiliza uma estratégia diferente para a contratação, alguns são admitidos por indicação.

As diferenças entre os processos de contratação das organizações públicas e privadas estão na forma de ingresso, porque na instituição pública é rigorosa em seu conteúdo, e o concurso deve ter conformidade com a lei, e na organização privada não é tão exigente, porém em algumas empresas são elaboradas várias fases além da prova escrita, dinâmica em grupo, entrevistas. 
Quadro 2. Este processo deveria ser mudado?

\begin{tabular}{|l|c|l|c|}
\hline \multicolumn{2}{|c|}{ SETOR PÚBLICO } & \multicolumn{2}{c|}{ SETOR PRIVADO } \\
\hline Não & Frequência & \multicolumn{1}{c|}{ Evocã̃o } & Frequência \\
\hline Aprimorar mais & 6 & Sim & 5 \\
\hline É impessoal & 3 & Não & 2 \\
\hline Preserva-se ampla concorrência & 3 & Sem nepotismo, preferência & 1 \\
\hline Sim, os cargos comissionados & 2 & Anúncios na internet/Linkedin & 1 \\
\hline Concurso é o meio mais eficiente & 1 & $\begin{array}{l}\text { Confiar mais nsis pessoas e menos no } \\
\text { papel (currículo) }\end{array}$ & 1 \\
\hline Especificidade voltada à prática & 1 & $\begin{array}{l}\text { Contratar empresa de RH para } \\
\text { intermediar }\end{array}$ & 1 \\
\hline Estágio Prob.-instrum.de correção & 1 & $\begin{array}{l}\text { Contratar pessoas qualificadas e não } \\
\text { parentes }\end{array}$ & 1 \\
\hline Não oferecer cotas & 1 & Escassez de vagas & 1 \\
\hline Sim & 1 & Facilitar os processos & 1 \\
\hline & & Feedback aos interessados & 1 \\
\hline & & Não tem opinião formada & 1 \\
\hline & & Treinamento para quem recruta & 1 \\
\hline
\end{tabular}

Fonte: Dados da pesquisa

A maioria dos entrevistados do setor público acredita que o processo de contratação não precisa ser mudado por possuir impessoalidade e por preservar a ampla concorrência, mas que necessita ser aprimorado. Entretanto, em relação à contratação de comissionados, é importante que seja revisada a forma de ingresso. Já no setor privado, alguns dos respondentes acham que a contratação não precisa alterar, mas a maioria acha que sim, eles são contra o nepotismo, acham que os processos necessitam de mudanças para facilitar a contratação, dar feedback aos candidatos, entre outros.

Alguns dos entrevistados, tanto de instituições privadas quanto das públicas, acreditam que o processo de contratação deveria ser atualizado para que haja um melhor aproveitamento dos profissionais conforme suas habilidades e competências. A subjetividade que existe nas contratações dos comissionados no setor público e os que são indicados no setor privado torna essa contratação suspeita, por existir uma parcialidade por parte do contratante, o que causa desconforto para os que querem ingressar ou já estão nas organizações. 
Contratação de empresa especializada para admissão de pessoal para evitar a subjetividade.

Quadro 3. O que o órgão/empresa deveria inserir para melhorar os processos?

\begin{tabular}{|c|c|c|c|}
\hline \multicolumn{2}{|l|}{ SETOR PÚBLICO } & \multicolumn{2}{|l|}{ SETOR PRIVADO } \\
\hline Evocação & Frequência & Evocação & Frequência \\
\hline Maior eficiência & 2 & Contratação de empresa especializada & 3 \\
\hline Aplicação concursos específicos & 1 & Formação específica do contratado & 3 \\
\hline $\begin{array}{l}\text { Apresentar aos novos servidores as } \\
\text { atribuições }\end{array}$ & 1 & Diminuir acúmulo de papel & 2 \\
\hline Aprimorar a avaliação & 1 & $\begin{array}{l}\text { Aperfeiçoar o Departamento Gestão } \\
\text { Pessoas }\end{array}$ & 1 \\
\hline Capacitação dos servidores & 1 & Colocar na internet & 1 \\
\hline Cobrar questões do serviço & 1 & Entrevista para cargos mais altos & 1 \\
\hline Critérios de relacionamento social & 1 & Exige muito para pouco salário & 1 \\
\hline Critérios meritocráticos & 1 & Facilitar a comunicação & 1 \\
\hline Dinâmicas de grupo & 1 & $\begin{array}{l}\text { Favorecer pessoas que não possuem } \\
\text { muitos recursos }\end{array}$ & 1 \\
\hline Edital mais realista & 1 & $\begin{array}{l}\text { Inserir aqueles que nunca trabalharam } \\
\text { (treinar/orientar) }\end{array}$ & 1 \\
\hline Exigir produtividade mínima & 1 & $\begin{array}{l}\text { Permitir que o candidato participe das } \\
\text { atividades da empresa para avaliar se } \\
\text { quer ou não trabalhar lá }\end{array}$ & 1 \\
\hline Incluir cursos de formação eliminatório & 1 & Resoluções em dinâmicas & 1 \\
\hline Incluir fase classificatória & 1 & Sem nepotismo, de preferência & 1 \\
\hline Incluir questões dissertativas & 1 & Teste de sanidade mental & 1 \\
\hline Maior celeridade & 1 & & \\
\hline $\begin{array}{l}\text { Melhor aproveitamento das } \\
\text { qualidades/habilidades }\end{array}$ & 1 & & \\
\hline Perícia médica (critérios psicol.) & 1 & & \\
\hline $\begin{array}{l}\text { Possibilidade de escolha da área que vai } \\
\text { trabalhar }\end{array}$ & 1 & & \\
\hline Tornar o concurso público mais pessoal & 1 & & \\
\hline
\end{tabular}

Fonte: Dados da pesquisa

Para melhorar os processos das instituições públicas, os entrevistados sugeriram inserir maior eficiência e celeridade, tornar o concurso público mais pessoal com dinâmicas de grupo, inclusão de cursos de formação eliminatórios, maior celeridade no processo, edital mais realista e nas instituições privadas $25 \%$ dos entrevistados são a favor da contratação de empresa especializada para executar esse serviço, dimi- 
nuir o acúmulo de papel, favorecer pessoas que não possuem muitos recursos, aperfeiçoamento do setor de recursos humanos.

Os respondentes das duas instituições acreditam que a dinâmica em grupo auxiliaria na identificação de características importantes dos candidatos, e a aplicação de testes psicológicos. Algumas respostas foram divergentes em relação à pessoalidade e às metas, pois os entrevistados da instituição pública opinaram sobre a possibilidade de introdução desses quesitos, e os da instituição privada não concordaram com as respostas.

Segundo Cunha; Cavalcanti (2012), no setor público não é realizado qualquer teste que possa identificar as aptidões do candidato à função, o que pode resultar na contratação de pessoas com aptidões e habilidades que não venham a atender plenamente aos requisitos básicos e também é fundamental que os responsáveis pelos processos de contratação tenham qualificação, visto que uma falha nessa contratação pode gerar perdas, refletir na produtividade, desunião do grupo.

Conforme Chiavenato (2010), é importante que a empresa possua atrativos, como marca ou notoriedade, porque é um grande atrativo para os candidatos.

Quadro 4. Existem outros problemas na contratação que gostaria de relatar?

\begin{tabular}{|c|c|c|c|}
\hline \multicolumn{2}{|l|}{ SETOR PÚBLICO } & \multicolumn{2}{|l|}{ SETOR PRIVADO } \\
\hline Evocação & Frequência & Evocação & Frequência \\
\hline $\begin{array}{l}\text { Contratação de cargos de livre } \\
\text { provimento (comissão) }\end{array}$ & 1 & Indicação (bons profissionais) & 4 \\
\hline Dificilmente exonera & 1 & $\begin{array}{l}\text { Indicação (facilita o favorecimento- } \\
\text { contrata maus funcionários) }\end{array}$ & 3 \\
\hline Falhas quanto ao perfil profissional & 1 & Não & 2 \\
\hline Falta capacidade de se relacionar & 1 & $\begin{array}{l}\text { Dono/entrevistador não conhece os } \\
\text { requisitos }\end{array}$ & 1 \\
\hline Falta capacidade de trabalhar em equipe & 1 & $\begin{array}{l}\text { Muitas fases no processo de } \\
\text { contratação }\end{array}$ & 1 \\
\hline $\begin{array}{l}\text { Há necessidade de aperfeiçoar os } \\
\text { métodos de aval. Desempenho }\end{array}$ & 1 & $\begin{array}{l}\text { Perde-se muito tempo no processo de } \\
\text { seleção }\end{array}$ & 1 \\
\hline Muitas vezes são determinados pelas & 1 & Ser transparente quanto às funções & 1 \\
\hline Não & 1 & Testes com psicólogos & 1 \\
\hline $\begin{array}{l}\text { Necessário abrir mão de aptidões e } \\
\text { vocações }\end{array}$ & 1 & & \\
\hline Sem traquejo/sem postura & 1 & & \\
\hline $\begin{array}{l}\text { Verificar se os funcionários continuam } \\
\text { produtivos, após o período de } \\
\text { estabilidade }\end{array}$ & 1 & & \\
\hline
\end{tabular}

Fonte: Dados da pesquisa 
Nessa questão, os entrevistados do setor público responderam que existem falhas quanto ao perfil profissional, muitos sem traquejo, sem postura, falta capacidade de trabalhar em equipe e de se relacionar, seria interessante a verificação da produtividade de cada servidor após o período de estabilidade, e que o método da avaliação de desempenho pudesse ser aperfeiçoado. No setor privado, $33 \%$ dos entrevistados acreditam que a indicação consegue atingir bons profissionais, porém $25 \%$ discordaram dessa opinião. Outros acham que, às vezes, o dono/entrevistador não conhece os requisitos necessários, é preciso diminuir as fases do processo de contratação e ser transparente quanto às funções a serem exercidas.

Considerando o retorno dos respondentes, verificou-se que, nas organizações públicas seria interessante verificar, após o candidato tomar posse do cargo, a capacidade de se relacionar com as pessoas, suas experiências anteriores, e nas organizações privadas, seria conveniente se as empresas fossem mais claras em relação às atribuições dos cargos e que o processo de contratação se tornasse mais direto.

Quadro 5. Quais as vantagens e desvantagens de trabalhar no Setor Público ou Privado?

\begin{tabular}{|c|c|c|c|}
\hline \multicolumn{2}{|l|}{ SETOR PÚBLICO } & \multicolumn{2}{|l|}{ SETOR PRIVADO } \\
\hline Evocação & Frequência & Evocação & Frequência \\
\hline Estabilidade & 12 & Liberdade para crescer na empresa & 4 \\
\hline Cultura menos rígida & 3 & $\begin{array}{l}\text { Considerar a área de conhecimento } \\
\text { específico }\end{array}$ & 1 \\
\hline Salário & 3 & Critérios confusos & 1 \\
\hline Acomodação & 1 & Demissão inesperada & 1 \\
\hline Ambiente menos competitivo & 1 & Diversificar os processos & 1 \\
\hline Burocracia & 1 & Exigente & 1 \\
\hline Evolução na carreira (s/mérito) & 1 & Experiência & 1 \\
\hline Falta motivação & 1 & Mobilidade & 1 \\
\hline Lentidão nos processos & 1 & Os beneficios estimulam a trabalhar bem & 1 \\
\hline $\begin{array}{l}\text { Não existe critério de evolução na } \\
\text { carreira por mérito }\end{array}$ & 1 & Paga direito & 1 \\
\hline Qualidade de vida & 1 & Paga pouco & 1 \\
\hline Rigidez hierárquica/legislativa & 1 & Possibilidade de empreender & 1 \\
\hline Sem metas & 1 & Quando entra por indicação & 1 \\
\hline Tranquilidade no ambiente de trabalho & 1 & Registro na carteira garante direitos & 1 \\
\hline & & Riscos maiores & 1 \\
\hline & & Sem concurso & 1 \\
\hline & & Sem estabilidade & 1 \\
\hline & & Sem reconhecimento & 1 \\
\hline & & Trabalha muito & 1 \\
\hline
\end{tabular}

Fonte: Dados da pesquisa 
A vantagem no setor público, conforme o questionário aplicado, é a estabilidade no cargo, valor do salário, cultura menos rígida, qualidade de vida, enquanto que no setor privado o empregado possui grande possibilidade de crescimento, diversificar os processos, e não é exigido concurso público. Em relação às desvantagens na organização pública, há rigidez hierárquica e legislativa, o servidor se acomoda, não existe critério de evolução na carreira, e na organização privada os critérios de seleção são confusos, não possui estabilidade, paga pouco e não há reconhecimento.

A diferença entre os processos de contratação das organizações está na estabilidade que o candidato adquire após três anos de efetivo exercício no setor público, o que não acontece no setor privado, em que o candidato é submetido à experiência de 90 dias, mas que pode ser dispensado a qualquer momento, o que acaba desmotivando-o. Para outros pesquisados, é necessário que as instituições reconheçam o desempenho de seus colaboradores e concedam um salário diferenciado.

Quadro 6. Por que escolheu este órgão/empresa?

\begin{tabular}{|l|c|l|c|}
\hline \multicolumn{2}{|c|}{ SETOR PÚBLICO } & \multicolumn{2}{c|}{ SETOR PRIVADO } \\
\hline Evocação & Frequência & \multicolumn{1}{c|}{ Evocação } & Frequência \\
\hline Grandeza da instituição & 2 & Salário & 6 \\
\hline Melhor concurso no qual passou & 2 & Estava num péssimo emprego & 3 \\
\hline Oportunidade & 2 & Oportunidade novo aprendizado & 3 \\
\hline Salário & 2 & Benefícios & 2 \\
\hline Cargo atendia minhas expectativas & 2 & Empresa grande & 2 \\
\hline Conveniência & 1 & Forma de ingresso é mais fácil & 2 \\
\hline $\begin{array}{l}\text { Gosta do trabalho realizado de } \\
\text { auditoria/fiscalização }\end{array}$ & 1 & Atração pelo serviço a ser executado & 1 \\
\hline & & Carga horária & 1 \\
\hline & & Conforme requisitos & 1 \\
\hline
\end{tabular}

Fonte: Dados da pesquisa

A maior parte dos entrevistados do setor público escolheu o órgão por oportunidade, tamanho da instituição, salário, cargo a ocupar ou porque passou, e no setor privado, $50 \%$ dos entrevistados escolheram a empresa em que estão atualmente também por causa do salário oferecido, estavam em um emprego não muito bom, e a oportunidade de novo aprendizado. 
Quadro 7. Você está satisfeito com este emprego?

\begin{tabular}{|c|c|c|c|}
\hline \multicolumn{2}{|c|}{ SETOR PÚBLICO } & \multicolumn{2}{|l|}{ SETOR PRIVADO } \\
\hline Evocação & Frequência & Evocação & Frequência \\
\hline Sim & 12 & Sim & 9 \\
\hline Ambiente bom & 1 & Precisa melhorar a gestão & 2 \\
\hline Boa estrutura & 1 & Precisa melhorar a organização & 2 \\
\hline Recebo em dia & 1 & $\begin{array}{l}\text { Insatisfeito com a quantidade de horas } \\
\text { de trabalho exigidas }\end{array}$ & 1 \\
\hline Sim, mas busco outras atividades & 1 & $\begin{array}{l}\text { Insatisfeito porque trabalha aos finais de } \\
\text { semana }\end{array}$ & 1 \\
\hline & & Mais ou menos & 1 \\
\hline & & Melhorar a reputação & 1 \\
\hline & & Precisa padronizar os processos & 1 \\
\hline & & Procurando outros melhores & 1 \\
\hline & & $\begin{array}{l}\begin{array}{l}\text { Satisfeito com o processo seletivo } \\
\text { (democrático) }\end{array} \\
\end{array}$ & 1 \\
\hline & & Satisfeito com o salário & 1 \\
\hline & & Satisfeito com os benefícios & 1 \\
\hline & & Satisfeito só com as pessoas & 1 \\
\hline & & Se sentindo subutilizado & 1 \\
\hline
\end{tabular}

Fonte: Dados da pesquisa

Os respondentes da instituição pública, 100\% estão satisfeitos com o cargo ocupado, mas com algumas ressalvas como: buscar outras atividades, porque a estrutura é boa e o ambiente também e recebe o salário em dia. Já na instituição privada, $75 \%$ estão satisfeitos, mas que a empresa precisa melhorar a gestão, organização, processos e a reputação, satisfeito com os benefícios e insatisfeito com as horas trabalhadas em finais de semana.

As organizações, tanto pública quanto privada necessitam melhorar a sua imagem para atrair novos talentos e candidatos mais preparados. Esse aperfeiçoamento poderia ocorrer com o auxílio da transparência, probidade e seriedade que as instituições divulgam ou publicam para o conhecimento de todos.

\section{CONSIDERAÇÕES FINAIS}

O objetivo principal deste trabalho foi demonstrar os diferentes aspectos do processo de contratação na Organização Pública e na Privada, 
com o intuito de aprimorar o entendimento em relação aos processos. E, para tal, foi realizada a pesquisa de campo, com abordagem qualitativa por meio de entrevistas que foram feitas com os colaboradores de ambas as instituições.

Os principais resultados revelaram que o objetivo da pesquisa foi alcançado por meio das respostas e possíveis soluções narradas pelos stakeholders, como no Setor Público: alteração na Lei para diminuir a porcentagem de comissionados, inclusão no edital de concurso de uma $2^{\mathrm{a}}$ fase classificatória com testes psicológicos e também para verificação da capacidade de se relacionar com pessoas e no Setor Privado: para que não haja desvio de função, ao anunciar a vaga, deixar claro o cargo, funções e experiência necessária, pesquisa de satisfação para saber a opinião dos colaboradores e fornecedores visando melhorar a imagem da empresa para atrair colaboradores capacitados, oferecer $f e$ edback aos candidatos não aprovados, contratação de empresa especializada para admissão de pessoal.

Em face do exposto, as implicações mais significativas são de natureza empírico/gerencial, visto que durante a realização da pesquisa foi constatada a necessidade de mudanças que favoreceriam o desempenho das organizações e dos colaboradores. São núcleos empíricos e gerenciais mais convenientes com as necessidades das organizações na atualidade (FLEURY; FLEURY, 2001).

Para estudos futuros, é sugerido ampliar a amostra para outras revisões de literatura, aumentar o período que possibilite uma visão mais globalizada da utilização dos métodos de pesquisa, podendo apresentar grandes contribuições, por exemplo, permitir novas contribuições metodológicas na área e ampliar a análise dos resultados e, por fim, a realização de futuras pesquisas ligando o objeto de pesquisa com as escolhas metodológicas que se revelem importantes para que os profissionais e gestores da área de Recursos Humanos e Gerencial tenham mais clareza sobre o tema.

Depreende-se que nos processos de contratação de pessoal algumas melhorias na Instituição Pública, por exemplo, introduzir testes no processo seletivo para cargos comissionados ou dinâmica em grupo, 
ou então, na Instituição Privada, tornando a seleção menos pessoal ou treinamento para o responsável pela contratação auxiliariam no processamento, como um todo, com resultados positivos para as instituições, na retenção de talentos, no aprimoramento da gestão.

\section{REFERÊNCIAS}

ALMEIDA, M. S. Elaboração de projeto, TCC, dissertação e tese: uma abordagem simples, prática e objetiva. São Paulo: Atlas, 2011.

BRASIL. Constituição da República Federativa do Brasil de 1988. Disponível em: $<$ http://www.planalto.gov.br/ccivil_03/constituicao/constituicaocompilado.htm>. Acesso em: 21 abr. 2017.

BRASIL. Decreto-Lei $\mathbf{n}^{0} . \mathbf{5 . 4 5 2}$, de $\mathbf{1}^{\mathbf{0}}$. de maio de 1943. Aprova a Consolidação das Leis do Trabalho. Disponível em: <http://www.planalto.gov.br/ccivil_03/decreto-lei/Del5452.htm>. Acesso em: 26 fev. 2017.

BRASIL. Lei $\mathbf{n}^{\mathbf{0}} \mathbf{. 8 . 6 6 6}$, de 21 de junho de 1993. Regulamenta o artigo 37, inciso XXI, da Constituição Federal, institui normas para licitações e contratos da Administração Pública e dá outras providências. Disponível em: $<$ http:// www.planalto.gov.br/ccivil_03/leis/L8666compilado.htm.> Acesso em: 19 mai. 2017.

BRASIL. Lei $\mathbf{n}^{\mathbf{0}} \mathbf{\cdot 1 0 . 2 6 1}$, de 28 de outubro de 1968. Dispõe sobre o Estatuto dos Funcionários Públicos Civis do Estado. Disponível em: $<$ http://www.al.sp. gov.br/repositorio/legislacao/lei/1968/compilacao-lei-10261-28.10.1968. html> Acesso em: 21 abr. 2017.

BURGESS, P. W.; SIMONS, J. S. Theories of frontal lobe executive function: clinical applications. In: HALLIGAN, P. W.; WADE, D. T. Effectiveness of rehabilitation for cognitive deficits. Oxford: Oxford University, 2005.

CARVALHO, A. V.; NASCIMENTO, L. P.; SERAFIM, O. C. G. Administração de Recursos Humanos, 2. ed. São Paulo: Cengage Learning, 2016.

CERVO, A. L. Metodologia Científica, 6. ed. São Paulo: Pearson Prentice Hall, 2007. 
CHIAVENATO, I. Iniciação à Administração de Recursos Humanos, 4. ed. Barueri: Manole, 2010.

CHIAVENATO, I. Planejamento, Recrutamento e Seleção de Pessoal: como agregar talentos à empresa, 7. ed. Barueri: Manole, 2009.

COLLIS, J.; HUSSEY, R. Pesquisa em Administração: um guia prático para alunos de graduação e pós-graduação: um guia prático para alunos de graduação e pós-graduação, 2. ed. Porto Alegre: Bookman, 2005, 349p.

CRESWELL, J. W. Projeto de Pesquisa: métodos qualitativos, quantitativos e misto. Porto Alegre: Artmed, 2010.

CUNHA, A. S.; CAVALCANTI, F. R. "Recrutamento e Seleção de Pessoal: análise comparativa entre a iniciativa privada e a pública." Revista Espaço Acadêmico, Maringá, nº 131, p. 76 a 80, abril de 2012. Disponível em: <http:// periodicos.uem.br/ojs/index.php/EspacoAcademico/article/view/14568> Acesso em: 19 mai. 2017.

DESSLER, G. Administração de Recursos Humanos, 2. ed. São Paulo: Prentice Hall, 2003. Disponível em: <http://fmn.bv3.digitalpages.com.br/ users/publications/9788587918277/pages/105> Acesso em: 22 out. 2017.

EBC Agência Brasil. Reforma trabalhista: saiba o que muda e quais profissões serão afetadas. Disponível em: <http://agenciabrasil.ebc.com.br/geral/ noticia/2017-11/reforma-trabalhista-saiba-o-que-muda-e-quais-profissoes-serao-afetadas $>$ Acesso em 29 nov. 2017.

FILHO, D. P. Metodologia Científica, 6. ed. São Paulo: Futura, 1998.

FLEURY, M. T. L.; FLEURY, A. Construindo o conceito de Competência. RAC, edição especial 2001.

FRANCO, M. L. P. B. Análise de conteúdo/ Maria Laura Barbosa Franco, 4. ed. Brasília: Liber Livro, 2012.

GIL, A. C. Como Elaborar Projetos de Pesquisa, 4. ed. São Paulo: Atlas, 2002.

MARTINS, I. G.; PASSOS, F. Manual de Iniciação ao Direito, 1. ed. São Paulo: Pioneira Thomson Learning, 2002. 
MARTINS, S. P. Instituições de Direito Público e Privado, 6. ed. São Paulo: Atlas, 2006.

PEQUENO, A. Administração de Recursos Humanos, 1. ed. São Paulo: Pearson Education do Brasil, 2012.

PONTES, B. R. Planejamento, Recrutamento e Seleção de Pessoal, 3. ed. São Paulo: LTr, 2001.

Portal IG. Brasil Econômico. Desemprego atinge 13,5 milhões de brasileiros; maior taxa desde 2012. Disponível em: <http://economia.ig.com. br/2017-03-31/desemprego-dados-ibge.html> Acesso em: 06 mai. 2017.

Que conceito. Conceito de Setor privado. Disponível em: $<$ http://queconceito.com.br/setor-privado> Acesso em 26 nov. 2017.

SEVERINO, A. J. Metodologia do Trabalho Científico, 23. ed. São Paulo: Cortez, 2007.

Sua Pesquisa. Com. Causas do Desemprego. As Principais causas do Desemprego no Brasil e no Mundo, pleno emprego. Disponível em: $<$ http:// www.suapesquisa.com/economia/causas_desemprego.htm $>$ Acesso em: 18 mai. 2017.

Uol Economia. Novas regras trabalhistas: o que pode não "pegar" entre as empresas...-

Disponível em: <https://economia.uol.com.br/noticias/redacao/2017/11/13/ novas-regras-trabalhistas-o-que-pode-nao-pegar-entre-as-empresas.htm> Acesso em 26 nov. 2017.

Valor Econômico. Taxa de Desemprego fica em 13,3\% no trimestre até maio, mostra IBGE. Disponível em: <http://www.valor.com.br/brasil/5022486/ taxa-de-desemprego-fica-em-133-no-trimestre-ate-maio-mostra-ibge> Acesso em 24 set. 2017. 


\section{SOBRE OS AUTORES}

Giseli Passador Lombardi

Advogada, Mestre em Educação e professora da Universidade Guarulhos

CV: http://lattes.cnpq.br/5034124479385450

giselipassador@gmail.com

Eliane Suguimoto Laureano

Tribunal de Contas do Estado de São Paulo. Bacharel em Administração pela Universidade Guarulhos.

CV: http://lattes.cnpq.br/5124390039675473

elisugui@gmail.com

Antonio Carlos Estender

Mestre em Administração pela Universidade Católica de Santos e professor da Universidade Guarulhos.

CV: http://lattes.cnpq.br/4902020098232180

estender@uol.com.br

Submetido em: 8-12-2017

Aceito em: 13-4-2018 